\title{
A sportomics strategy to analyze the ability of arginine to modulate both ammonia and lymphocyte levels in blood after high-intensity exercise
}

Luis Carlos Gonçalves ${ }^{1}$, Artur Bessa' ${ }^{1}$, Ricardo Freitas-Dias ${ }^{1}$, Rafael Luzes ${ }^{1,2}$, João Pedro Saar Werneck-de-Castro ${ }^{1,3}$, Adriana Bassini ${ }^{1,2+}$ and Luiz-Claudio Cameron ${ }^{1,2,4^{*+}}$

\begin{abstract}
Background: Exercise is an excellent tool to study the interactions between metabolic stress and the immune system. Specifically, high-intensity exercises both produce transient hyperammonemia and influence the distribution of white blood cells. Carbohydrates and glutamine and arginine supplementation were previously shown to effectively modulate ammonia levels during exercise. In this study, we used a short-duration, high-intensity exercise together with a low carbohydrate diet to induce a hyperammonemia state and better understand how arginine influences both ammonemia and the distribution of leukocytes in the blood.

Methods: Brazilian Jiu-Jitsu practitioners (men, $n=39$ ) volunteered for this study. The subjects followed a lowcarbohydrate diet for four days before the trials and received either arginine supplementation $\left(100 \mathrm{mg} \cdot \mathrm{kg}^{-1}\right.$ of body mass. day ${ }^{-1}$ ) or a placebo. The intergroup statistical significance was calculated by a one-way analysis of variance, followed by Student's t-test. The data correlations were calculated using Pearson's test.

Results: In the control group, ammonemia increased during matches at almost twice the rate of the arginine group ( $25 \mathrm{mmol} \cdot \mathrm{L}^{-1} \cdot \mathrm{min}^{-1}$ and $13 \mu \mathrm{mol} \cdot \mathrm{L}^{-1} \cdot \mathrm{min}^{-1}$, respectively). Exercise induced an increase in leukocytes of approximately $75 \%$. An even greater difference was observed in the lymphocyte count, which increased 2.2-fold in the control group; this increase was partially prevented by arginine supplementation. The shape of the ammonemia curve suggests that arginine helps prevent increases in ammonia levels.
\end{abstract}

Conclusions: These data indicate that increases in lymphocytes and ammonia are simultaneously reduced by arginine supplementation. We propose that increased serum lymphocytes could be related to changes in ammonemia and ammonia metabolism.

Keywords: White blood cells, Granulocytes, Amino acids, Immune response, Short-duration exercise

\footnotetext{
*Correspondence: cameron@unirio.br

${ }^{\dagger}$ Equal contributors

'Laboratory of Biochemistry of Proteins, Federal University of State of Rio de

Janeiro, Av. Pasteur 296, CEP: 22290-240, Rio de Janeiro, Brazil

${ }^{2}$ Institute of Genetics and Biology, Federal University of Uberlândia, Av. João

Naves de Ávila 2121, CEP: 38408-100, Uberlândia, Brazil

Full list of author information is available at the end of the article
} 


\section{Background}

We previously proposed that exercise can be used as a tool to study the interactions between metabolic stress and the immune system [1,2]. Exercise can be employed as a model of the temporary immunosuppression that occurs after severe physical stress [3,4]. Exercise impacts the immune response, and these effects depend on the intensity, duration and nature of the exercise [5]. Changes in the number of white blood cells (WBC) in circulation were previously described in various exercise experiments, including both high- and low-intensity exercises [6,7]. The immunological effects caused by exercise have been associated with the mechanical release of leukocytes from the vessel walls due to increased blood flow or catecholamine release, which is a mechanism that can be partially explained by cell adhesion signaling $[8,9]$.

Hyperammonemia can be caused by urea cycle enzyme diseases, liver failure and exercise (for a recent review, see Wilkinson et al. [10]). In general, ammonia (which here refers to the sum of $\mathrm{NH}_{3}$ and $\mathrm{NH}_{4}^{+}$) is highly toxic to humans, and hepatocytes maintain the blood concentration of ammonia in the $20-100 \mu \mathrm{M}$ range. Ammonia can cross the blood-brain barrier and reach levels greater than $800 \mu \mathrm{mol} / \mathrm{L}$ inside the central nervous system (CNS), which can lead to a decrease in cerebral function, neuropsychiatric disorders and death [11]. Ammonia-mediated excitotoxicity has been proposed as a mechanism for spreading damage in the CNS [12].

Ammonia levels change over time, and data obtained from exercises of different intensities have been used to help explain the effects of transient hyperammonemia $[6,13]$. A rise in ammonemia occurs after different types of exercise, and these changes can be managed by supplementation with amino acids or carbohydrates, which interfere with ammonia metabolism [13,14]. In addition, we recently showed that a mixture of amino acids and ketoacids can interfere with the increase in ammonemia in both human and rat exercise studies [15,16].

Arginine (Arg) has a versatile metabolic role in cell function. It can be used as a precursor not only for protein synthesis but also for the synthesis of nitric oxide, urea, and other amino acids, such as glutamate [17]. Exercise studies show that mammals that receive Arg supplementation have greater concentrations of urea cycle intermediates in the serum, less lactatemia and better ammonia buffering than controls [18,19]. Arg supplementation has also been described as an immune system stimulator, mainly in the production of T cells $[20,21]$.

We used a sportomics approach to understand exerciseinduced cellular and metabolic modifications in a field experiment [22,23]. Sportomics is the use of "-omics" sciences together with classical clinical laboratory analyses (e.g., enzymatic determinations, ELISA and western blotting) to understand sport-induced modifications. The suffix "-ome" means that all constituents are considered collectively; therefore, for example, proteomics is the study of all proteins, and metabolomics is the study of all metabolic processes. We treated data in a systemic way and generated a large amount of data in a type of nontarget analysis using a top-down approach.

Here, we combined a high-intensity exercise with a previously described low-carbohydrate diet [16], which act synergistically to increase ammonemia, to better understand the ability of arginine to modulate both ammonia and leukocyte changes in the blood.

\section{Methods \\ Subjects}

World-class Brazilian Jiu-Jitsu competitors ( $\mathrm{n}=50$ males) volunteered to take part in this double-blind, randomized study. Because they had difficulty in following the diet, 11 subjects withdrew from the study. The enrolled athletes had a minimum of three years of Jiu-Jitsu experience. Users of pharmaceutical drugs or nutritional ergogenic aids were excluded from the study. The included athletes had not sustained any injuries in the previous six months.

The subjects were randomly divided into two groups. The arginine-supplemented group ( $R G, n=16)$ ingested $100 \mathrm{mg} \cdot \mathrm{kg}^{-1}$ of body mass $\cdot$ day $^{-1}$, and the control group (PG, $\mathrm{n}=23$ ) took $100 \mathrm{mg} \cdot \mathrm{kg}^{-1}$ of body mass $\cdot \mathrm{day}^{-1}$ of lactose with supplement doses as described previously $[18,24]$. Each athlete received packs of indistinguishable capsules containing the daily doses and used them for four days, including the day of the experiment.

The athletes were briefed about the aim and the protocol of the study. Informed written consent was obtained from all of the subjects, and the experiments were performed in accordance with the guidelines from the ethics committee for human research of the Universidade Federal do Estado do Rio de Janeiro and the requirements for performing research on human subjects (Health National Council, Brazil, 1996).

\section{Diet}

Athletes from both groups followed a low-carbohydrate diet (LCD) as previously described [16]. LCD adherence was verified by diet evaluation before the experiment and ketonuria. The athletes refrained from caffeine, ethanol and smoking for three days before the trials. To decrease the glycogen stores, the experiment was conducted after $12 \mathrm{~h}$ of fasting. The last supplement doses were given $90 \mathrm{~min}$ before the match.

\section{Experiment}

The participants engaged in a six-minute Brazilian JiuJitsu match in full gear. The matches were performed at 
similar temperatures and levels of humidity and began with the athletes kneeling to avoid injuries from falling. The subjects were instructed to maintain high mobility and avoid finishing the match. The opponent in the match was not subjected to an LCD and was exchanged for a rested opponent after 3 minutes of elapsed match time to maintain an intensity that was as high as possible in the study subjects. The matches occurred between individuals in the same weight category.

The exercise intensity was evaluated during a pilot experiment, and the athletes displayed a range from $85 \%$ to $90 \%$ of their maximum heart rate; we also observed that the match promoted a similar kinetic ammonia serum increase for all athletes (data not shown).

\section{Blood sampling}

Blood samples were collected following venipuncture at rest immediately before and $\sim 1,3,5,7$ and 10 min after the match. Because the fight took 6 minutes, the data in the figures are shown with times 7, 9, 11, 13 and 16 min after the beginning of the exercise. The pre-match sample was collected just before the exercise began, which occurred $90 \mathrm{~min}$ after the last dose of arginine or lactose, and the first post-match sample was collected immediately after the match ended (30-60 sec). Blood was collected in tubes containing $\mathrm{K}_{3}$ EDTA and refrigerated until the hematological analysis (up to $2 \mathrm{~h}$ ).

The blood analyses were performed at least in triplicate. Red blood cells and platelets were also measured. Samples for the biochemical assay were collected in tubes with a coagulation enhancer and splitting gel (Vacuette, Greiner Bio-One) and immediately centrifuged $(3,000 \times \mathrm{g}$, $10 \mathrm{~min}$ ). The blood serum was aliquoted and stored in liquid nitrogen for future analyses. The sera were analyzed using clinical kits for the following muscle injury markers and biochemical variables: ammonia, creatine kinase $(\mathrm{CK})$, creatine kinase-MB (CK-MB), aspartate aminotransferase (AST), alanine aminotransferase (ALT), $\gamma$ glutamyltransferase $(\gamma \mathrm{GT})$, lactate dehydrogenase $(\mathrm{LDH})$, alkaline phosphatase (ALP), glucose, urea, creatinine, urate, total protein, albumin, bilirubin, globulins, and serum hemoglobin. No changes in plasma volume were detected during the experiment.

\section{Calculations and statistics}

The area under the curve (AUC) for the blood ammonia data for each individual in each treatment was determined using the equation $\mathrm{AUC}=\{\mathrm{Ai}(\mathrm{Ti}+1-\mathrm{Ti})+(1 / 2)$ $(\mathrm{Ai}+1-\mathrm{Ai})(\mathrm{Ti}+1-\mathrm{Ti})\}$, where $\mathrm{A}$ denotes ammonia concentration $(\mu \mathrm{mol} / \mathrm{L})$ and $\mathrm{T}$ denotes time $(\mathrm{min})$. The blood ammonia accumulation rate during the match was calculated by the difference between the ammonia concentrations before and approximately 1 minute after exercise divided by 6 minutes.
The data are shown as the mean and standard error. The data were normalized to the pre-exercise values. The intergroup statistical significance was calculated by a oneway analysis of variance (ANOVA), and the intragroup significance was established by Student's $t$-test. The data correlations were calculated using Pearson's test. Significant differences were assumed at $\mathrm{P}<0.05$.

\section{Results}

\section{Proteins and injury markers}

To ensure that the athletes were at similar training levels and had similar liver integrities, we measured the classic muscle and liver injury markers. The athletes of both groups had similar anthropometric values (Table 1). Despite the high levels of classic muscle injury markers, such as CK (EC 2.7.3.2) and LDH (EC 1.1.1.27), the concentrations of these enzymes in the blood did not change after the match. The liver injury markers ALP (EC 3.1.3.1) and $\gamma \mathrm{GT}$ (EC 2.3.2.2) also remained stable in both groups. The same stability was observed with the less specific markers AST (EC 2.6.1.1) and ALT (EC 2.6.1.2) (Table 2). The amount of globulins in the blood increased in both groups after exercise, with an $11 \%$ increase in the RG and a 15\% increase in the PG (Table 2).

\section{Ammonia and its metabolites}

To evaluate the consequences of an increase in the blood ammonia concentration induced by high-intensity exercise, we used a Brazilian Jiu-Jitsu match as an exercise stress inducer (Figure 1). In the control group, ammonemia increased during the match at almost twice the rate of the RG $\left(25 \mu \mathrm{mol} \cdot \mathrm{L}^{-1} \cdot \mathrm{min}^{-1}\right.$ and $13 \mu \mathrm{mol} \cdot \mathrm{L}^{-1} \cdot \mathrm{min}^{-1}$, respectively). The AUC analysis showed that the RG maintained lower ammonemia ( $30 \%)$ compared with the controls (Figure 2).

We measured the glycemia changes as a control for Arg supplementation. The match led to a $30 \%$ increase in glycemia in both groups, and glycemia remained high until the last measurement, which occurred ten minutes after the match (Figure 3A). To evaluate the urea increase due to the higher ammonia production, we measured the urea level in the blood. There were no differences in the blood urea concentration between the groups either before or after exercise (Figure 3B). Ammonia production

Table 1 Age and anthropometric measurements in Brazilian Jiu-Jitsu fighters assigned to the PG and RG

\begin{tabular}{lcccc}
\hline & PG & Range & RG & Range \\
\hline Age (years) & $25.2 \pm 0.4$ & $21-28$ & $26.2 \pm 0.6$ & $23-29$ \\
\hline Weight $(\mathrm{kg})$ & $82.2 \pm 1.8$ & $70-103$ & $79.2 \pm 3.2$ & $65-120$ \\
\hline Height $(\mathrm{cm})$ & $177 \pm 1.0$ & $170-188$ & $175 \pm 1.4$ & $170-190$ \\
\hline
\end{tabular}

Values are the mean $\pm S E$ and the range. No significant differences were detected $(p>0.05)$. 
Table 2 Muscle and liver injury markers measured before (PRE) and after the match (POST)

\begin{tabular}{lccccc}
\hline & \multicolumn{2}{c}{ PG } & & \multicolumn{2}{c}{ RG } \\
\cline { 2 - 3 } \cline { 5 - 6 } & PRE & POST & PRE & POST \\
\hline CK (U/L) & $737.0 \pm 187.2$ & $1051.2 \pm 401.9$ & $559.1 \pm 128.3$ & $625.1 \pm 148.8$ \\
\hline CKMB (U/L) & $13.6 \pm 4.1$ & $36.0 \pm 13.5$ & & $12.2 \pm 2.0$ & $17.6 \pm 3.2$ \\
\hline LDH (U/L) & $390.0 \pm 41.9$ & $402.8 \pm 29.6$ & & $354.6 \pm 18.4$ & $388.3 \pm 17.9$ \\
\hline SGT (U/L) & $21.7 \pm 2.4$ & $21.7 \pm 2.7$ & $27.4 \pm 4.2$ & $30.2 \pm 4.4$ \\
\hline ALP (U/L) & $80.8 \pm 11.8$ & $88.1 \pm 12.0$ & $67.6 \pm 7.7$ & $74.6 \pm 7.4$ \\
\hline ALT (U/L) & $23.0 \pm 3.8$ & $26.2 \pm 3.2$ & $30.1 \pm 5.2$ & $29.9 \pm 5.1$ \\
\hline AST (U/L) & $52.7 \pm 17.9$ & $68.2 \pm 21.2$ & $36.0 \pm 3.7$ & $45.2 \pm 5.8$ \\
\hline Albumin (g/L) & $43.3 \pm 0.2$ & $46.0 \pm 0.2$ & & $45.9 \pm 0.2$ & $50.2 \pm 0.2$ \\
\hline Globulins (g/L) & $32.5 \pm 0.1$ & $38.0 \pm 0.1$ & $31.1 \pm 0.1 \#$ & $34.6 \pm 0.1 \#$ \\
\hline
\end{tabular}

PG, placebo group; RG, arginine group. Values are the mean $\pm S E$ and the range. No statistically significant inter- or intragroup differences were detected, except for globulins in response to exercise and to supplementation.

during high-intensity exercise is mainly due to AMP deamination, which leads to IMP. The final product of IMP metabolism is urate. There were no changes in the blood urate concentration between the groups either before or after the match (Figure 3C). None of the above metabolites showed changes in response to Arg supplementation when we compared the pre- and post-match levels (Figure 3).

\section{Blood cells}

The six minutes of exercise induced an increase in leukocytes of approximately $75 \%$ in both groups. This elevated level did not decrease in the ten minutes following the experiment and was similar between the groups (Figure 4A). To avoid misinterpretations due to volemic variations, we also evaluated the red blood cell counts. The packed cell volume was not altered by exercise (Figure 4B). We did not detect any differences in the red blood cell count, volume or hemoglobin content in response to either exercise or supplementation.

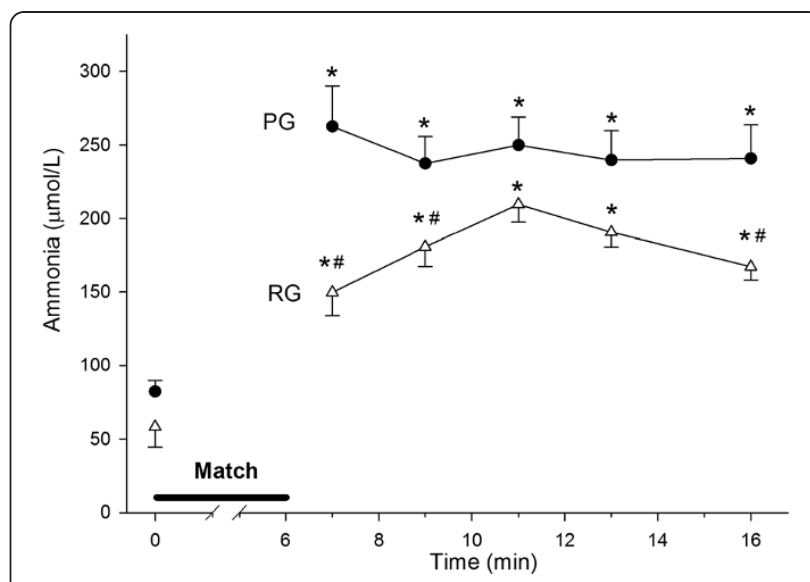

Figure 2 Blood ammonia concentration increases after a high-intensity exercise in an arginine supplementationdependent manner. A six-minute Jiu-Jitsu match was performed after a three-day $L C D$ by athletes who had received either arginine $(\mathrm{RG}, \Delta)$ or a placebo $(\mathrm{PG}, \bullet)$. Blood was collected before and after exercise and treated as described in the Materials and Methods. Control, $n=23$; Arginine, $n=16$. $\left(^{*}\right)$ denotes that the average \pm SE is different from the pre-exercise values; (\#) denotes a difference between the two experimental groups. The calculated area under the curve was $3397 \mu \mathrm{mol} / L \cdot \mathrm{min}-1$ for the placebo group and $2366 \mu \mathrm{mol} / \mathrm{L} \cdot \mathrm{min}-1$ for the arginine group.

Differential white blood cell analyses showed a distinct response to both exercise and Arg supplementation. The basophil counts rose two-fold in the PG but did not change in the RG (Figure 5A). The eosinophil counts were significantly different between the groups after the end of exercise (Figure 5B). However, neutrophils appeared not to respond significantly in either the PG or RG (Figure 5C). The exercise led to a 2.2-fold increase in the lymphocyte count. This increase was significantly reduced by Arg supplementation (Figure 6A).

To better understand the ammonia-lymphocyte relationship with Arg supplementation during exercise, we plotted the ammonia response to exercise against the lymphocyte count. The exercise-induced increases in
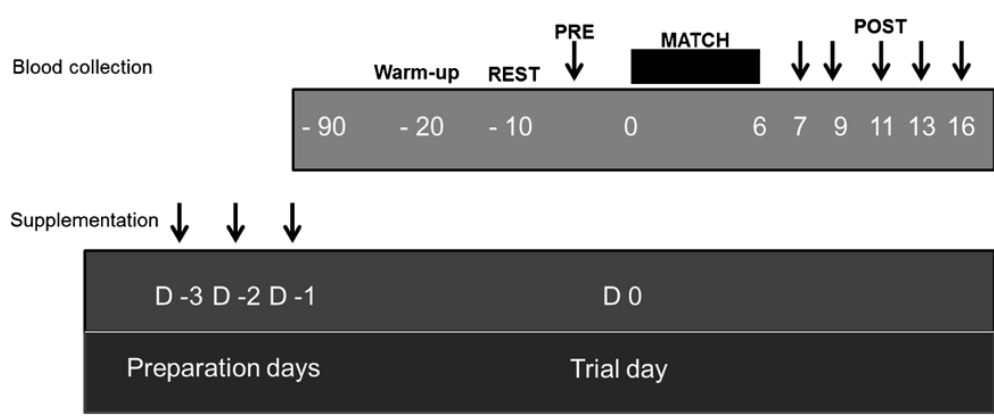

Figure 1 Experimental design. Before the experiment, the athletes were subjected to a four-day LCD as described in the Materials and Methods. Blood was collected before the athletes received supplementation (PRE). Warm-up and exercise protocols were performed, followed by six blood collections immediately after exercise (POST; 1, 3, 5, 7 and $10 \mathrm{~min}$ ). 


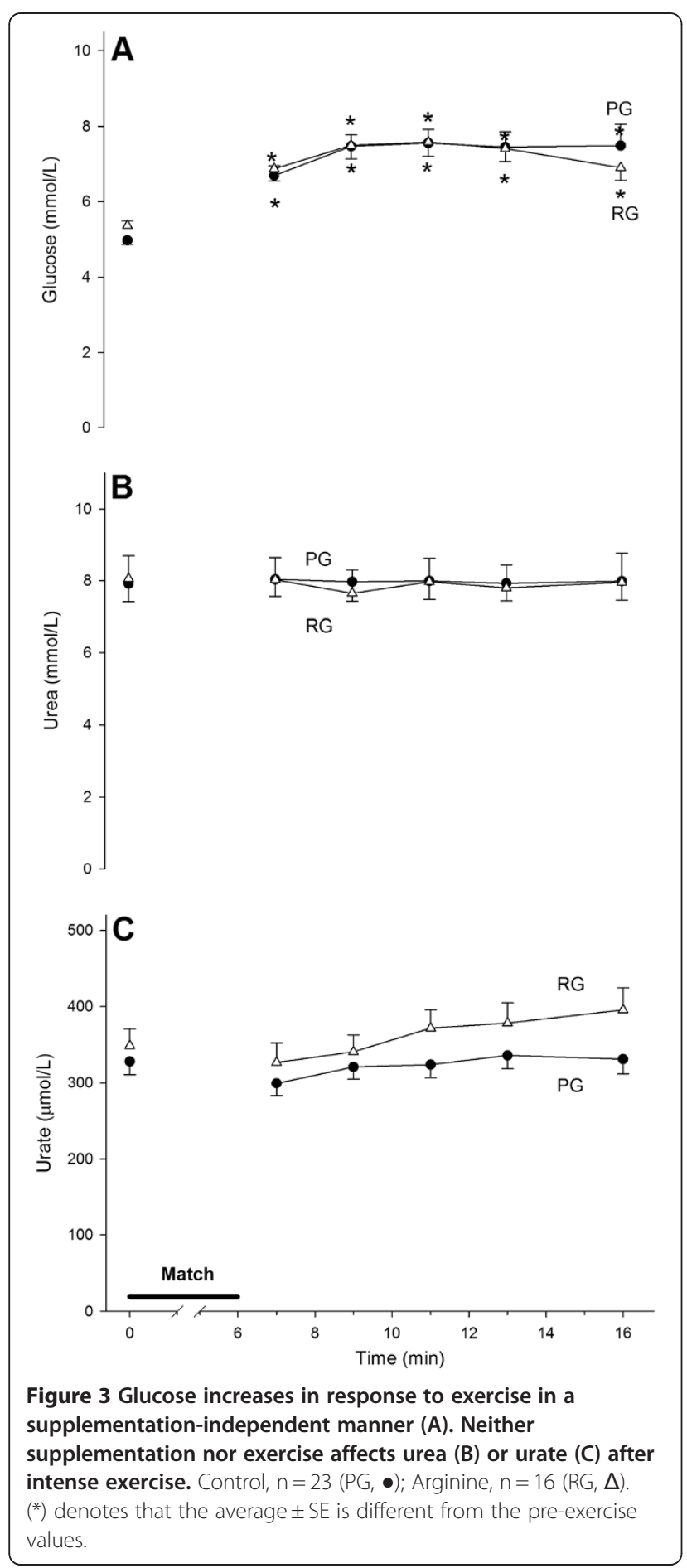

ammonia and the lymphocyte count were highly correlated. The lymphocyte count associated with the increase in ammonia was decreased by Arg supplementation (Figure 7).

\section{Discussion}

Ammonia has deleterious effects on many systems, including the CNS, and has been identified as a potential

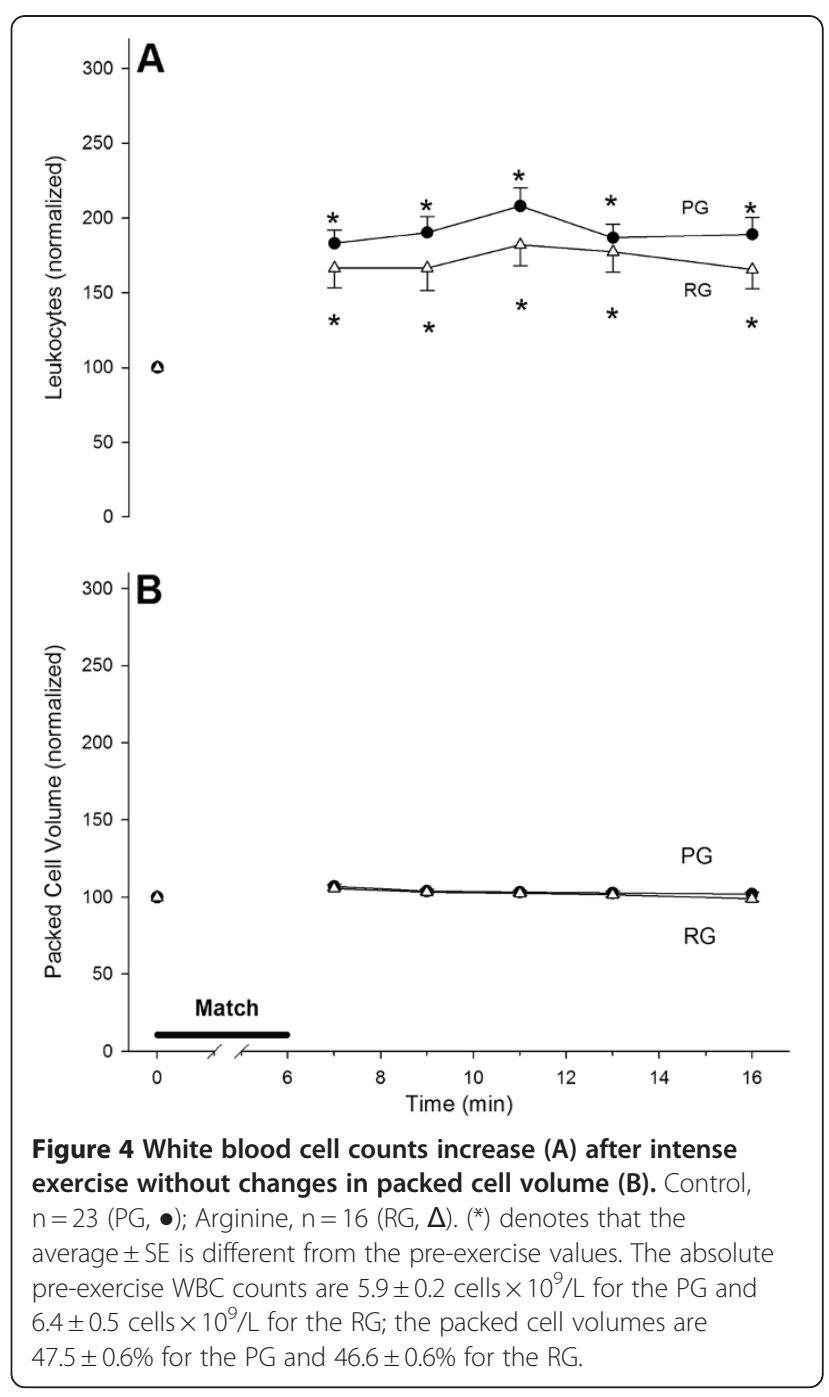

cause of central fatigue. Blood ammonia is normally in the range of $20-100 \mu \mathrm{M}$, and concentrations above this range have been correlated with the incidence of encephalopathy, coma and death [10]. During exercise, ammonemia can exceed $350 \mu \mathrm{M}$ without obvious symptoms [13]. In this study, we used an LCD (to deplete glycogen stores) combined with a Brazilian Jiu-Jitsu session using a sportomics protocol to investigate the increase in blood ammonia and changes in the white blood cell levels following exercise.

The blood ammonia increased four- to six-fold after a six-minute match and reached levels as high as $610 \mu \mathrm{M}$ in one individual. These values are higher than the published averages, even if we consider other match-based studies [6,25], which confirms that this experimental protocol is a powerful short-term metabolic stress inducer. The velocity of the ammonia increase was partially (50\%) retarded by previous Arg intake, and the total ammonia was lower in the RG. In addition, the 


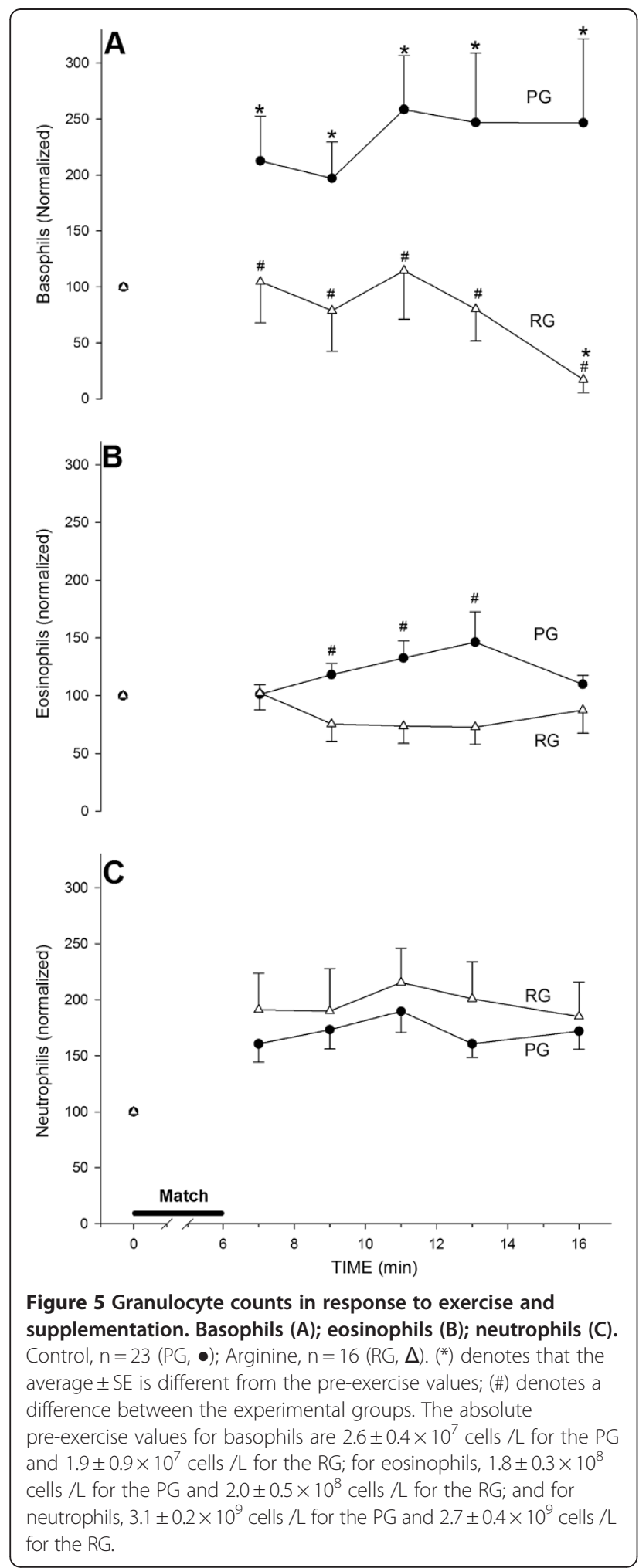

analysis of individual ammonia clearance suggests a greater velocity in the supplemented group.

An increase in blood ammonia depends on different factors, including glycogen stores, amino acid deamination

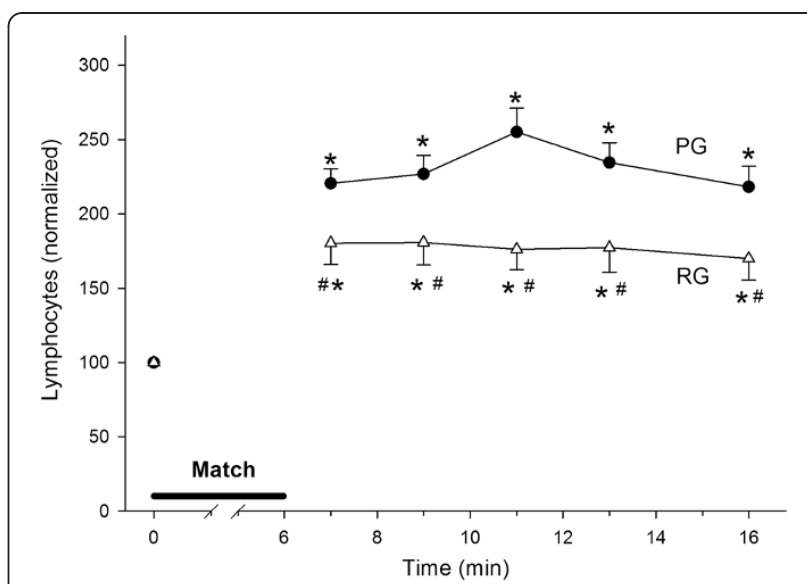

Figure 6 Exercise induces an increase in lymphocytes in an arginine supplementation-dependent manner. Control, $n=23$ $(P G, \bullet)$; Arginine, $n=16(R G, \Delta) .\left(^{*}\right)$ denotes that the average $\pm S E$ is different from the pre-exercise values. The absolute pre-exercise values are shown within the graphs. The absolute pre-exercise values for lymphocytes are $2.2 \pm 0.1 \times 10^{9}$ cells $/ L$ for the $P G$ and $2.9 \pm 0.3 \times 10^{9}$ cells $/ L$ for the RG (no statistically significant difference, $p=0.07$ ).

and glucose availability [26]. We used this knowledge as the rationale for depleting the glycogen stores using an LCD. In our study, blood glucose increased up to $30 \%$ in response to exercise and remained at this elevated level until the final measurement ten minutes after the match irrespective of Arg supplementation. This finding rules out an effect of Arg on ammonemia due to Arg supplementation-induced glucose production. The shape

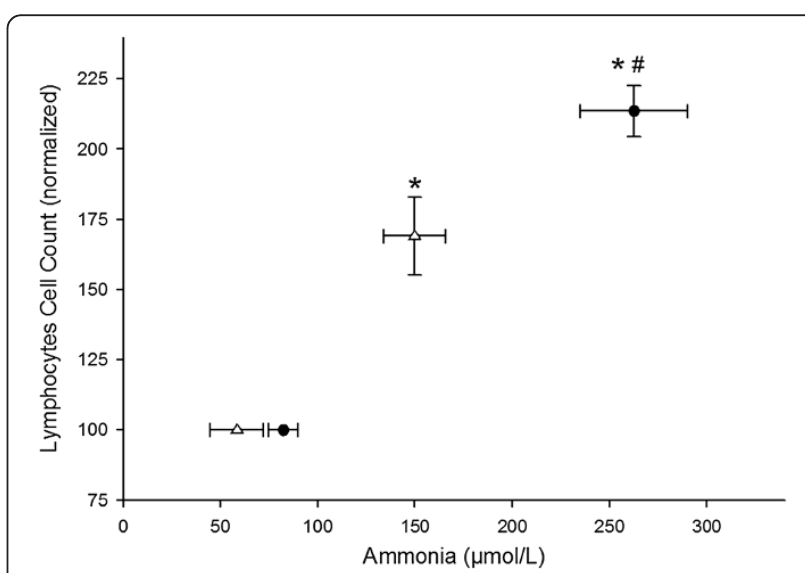

Figure 7 Ammonemia increase is related to the blood lymphocyte count. The lymphocyte count is plotted against ammonemia. ${ }^{*}$ ) denotes that the average $\pm \mathrm{SE}$ is different from the pre-exercise values; (\#) denotes a difference between the experimental groups. Pearson correlations indicate that the relationship between the lymphocyte count and ammonemia is indirect. The lymphocyte increases were normalized to pre-fight levels to ensure a better understanding of the results. Control, $n=23(P G, \bullet)$; Arginine, $n=16(R G, \Delta)$. 
of the ammonemia curve suggests that Arg promotes buffering against the ammonemia increase likely by increasing ammonia clearance via the promotion of higher levels of urea cycle intermediates, as previously described [18].

We performed a biochemical pre-evaluation of our subjects to assess the integrity of their liver function. The liver function of the athletes was assessed based on their hepatic metabolic function and hepatocyte integrity, which were measured by the presence of intracellular hepatocyte enzymes in blood. Neither blood urea nor urate production showed any significant differences between the groups before or after exercise. This finding is acceptable because we measured the total production of both metabolites in the blood over a short time period. The long-term supplementation of both glutamine and alanine increases the resting level of blood urea [13]. In this study, we did not find any differences in urea or urate at rest between the groups. Both groups had a similarly increased basal urea level compared with normal subjects due to the LCD. These data reinforce the possibility that Arg acts as a reservoir for increased ammonia detoxification instead of being used as a carbon skeleton donor.

Exercise has been proposed to have a biphasic effect on immune function [27], with various immune cell functions temporarily impaired following acute bouts of intense exercise [5]. In this study, we observed an increase in the number of leukocytes after exercise. We did not find changes in either packed cell volume, which is an internal control for volemic changes, or thrombocytes (data not shown). We did not detect a significant increase in the eosinophil or neutrophil count in response to either exercise or Arg supplementation. In contrast, we found a significant effect of supplementation on basophils and lymphocytes in response to exercise.

Distinct effects on white blood cells due to exercise have been reported in previous studies. In a study on heavy-resistance exercise, Kraemer et al. [28] reported a decrease in eosinophils, which was contradicted by later studies that showed an increase in the total leukocyte count without differences in specific leukocyte counts [29]. Even with an increase in the neutrophil count of $50-70 \%$ in some athletes, neutrophil levels did not change significantly in response to exercise in our study, which was expected based on previous reports [30]. Little is known about the response of granulocytes to acute exercise. However, some data have suggested that neutrophils increase following acute exercise, which is similar to the neutrophil increase caused by trauma [31], and that high-intensity exercise decreases neutrophil and thrombocyte adhesion [32]. These findings together can help explain our results.
An increase in leukocytes after acute exercise was extensively described in a review by Gleeson [5]. In our study, we found a 75-85\% increase in leukocytes. This increase was mainly due to an increase in lymphocytes, which agreed with a previous report [30]. Interestingly, we also observed protection against the leukocyte and lymphocyte increases in the RG. Carbohydrate supplementation decreases both leukocyte and lymphocyte trafficking during exercise and attenuates lymphocytosis after acute exhaustive resistance [33]. Our data rule out a protective effect of Arg against the leukocytosis that might occur due to changes in glycemia.

A previous report by Sureda et al. [21] showed that neutrophilia and lymphopenia occurred after exhaustive exercise with constant plasma concentrations of Arg and ornithine but decreased citrulline. Supplementation with $3 \mathrm{~g} \cdot$ day $^{-1}$ Arg can increase the availability of Arg, ornithine and citrulline [18]. Because we used $100 \mathrm{mg} \cdot \mathrm{kg}^{-1} \cdot \mathrm{day}^{-1}$ (6.5-12.0 g. day $\left.{ }^{-1}\right)$, the supplementation used in our experiments may have resulted in an increased reservoir of these urea cycle intermediates [18].

A limitation of our study is the absence of blood amino acid measurements. Indeed, in another set of data, we measured blood amino acid levels after Arg supplementation, showing that this time frame was sufficient for Arg absorption (unpublished data). In this study, we showed a high correlation between the increases in the lymphocyte count and blood ammonia, both of which were prevented by Arg supplementation. In an elegant study, Garg et al. [34] recently proposed that $\mathrm{T}$ cells could act in concert with glia to protect neurons. This protection occurs via the liberation of lactate and glutamate from $\mathrm{T}$ cells following the release of cysteine (a precursor of glutathione synthesis) by astrocytes to protect neurons and the release of lactate to feed the neurons. Previous reports have also shown metabolic protection from lymphocytes in target tissues, including the maintenance of cognition [35-37]. In addition, our data show that the increase in blood globulins is affected by Arg supplementation. Given these data, we propose that increases in serum lymphocytes could be related to changes in ammonemia and ammonia metabolism.

\section{Conclusions}

The modulation of arginine through supplementation in exercise is well established. In this study, we induced transitory hyperammonemia with a low carbohydrate diet and high intensity exercise to evaluate the changes in nitrogen metabolism.

Even with a six-fold increase in ammonemia during our protocol, we did not demonstrate either acute muscle damage or changes in glycemia. These data suggest that exercise is an efficient model to apply in sports medicine and nutrition. 
Here, we showed for the first time that arginine supplementation decreases both ammonemia and the lymphocyte response during intense exercise and that the use of this amino acid can be a strategy to modify metabolism during exercise.

\section{Competing interests}

The authors declare that they have no competing interests.

\section{Financial competing interests}

The authors declare that they have no financial competing interests.

\section{Authors' contributions}

LCG, ABessa, RFD, ABassini and LCC: essential contributions to the conception and design of the study protocol; acquisition, analysis and interpretation of data; and involvement in drafting of the manuscript. RL, JPSWC, ABassini and LCC: critical revisions for important intellectual content. All authors read and approved the final manuscript.

\section{Acknowledgements}

We wish to thank Dr. Mazon for his professional support during the performance of the tests and Dr. Anibal M Magalhães-Neto for his help with preparing the manuscript.

\section{Author details}

'Laboratory of Biochemistry of Proteins, Federal University of State of Rio de Janeiro, Av. Pasteur 296, CEP: 22290-240, Rio de Janeiro, Brazil. ${ }^{2}$ Institute of Genetics and Biology, Federal University of Uberlândia, Av. João Naves de Ávila 2121, CEP: 38408-100, Uberlândia, Brazil. ${ }^{3}$ Laboratory of Biology of Exercise, Federal University of Rio de Janeiro, Av. Carlos Chagas Filho 540, CEP: 21941-599, Rio de Janeiro, Brazil. ${ }^{4}$ University Castelo Branco, Av. Salvador Allende 6.700, CEP: 22780-160, Rio de Janeiro, Brazil.

Received: 10 October 2011 Accepted: 13 June 2012

Published: 26 June 2012

\section{References}

1. Bassini-Cameron A, Sweet E, Bottino A, Bittar C, Veiga C, Cameron LC: Effect of caffeine supplementation on haematological and biochemical variables in elite soccer players under physical stress conditions. $\mathrm{Br} J$ Sports Med 2007, 4(8):523-530.

2. Bessa A, Nissenbaum M, Monteiro A, Gandra PG, Nunes LS, Bassini-Cameron A, Werneck-de-Castro JP, de Macedo DV, Cameron LC: High-intensity ultraendurance promotes early release of muscle injury markers. Br J Sports Med 2008, 42(11):889-893.

3. Pedersen BK, Nieman DC: Exercise immunology: integration and regulation. Immunol Today 1998, 19(5):204-206.

4. Pedersen BK, Hoffman-Goetz L: Exercise and the immune system: regulation, integration, and adaptation. Physiol Rev 2000, 80(3):1055-1081.

5. Gleeson M: Immune function in sport and exercise. J Appl Physiol 2007, 103(2):693-699.

6. Degoutte F, Jouanel P, Filaire E: Energy demands during a judo match and recovery. Br J Sports Med 2003, 37(3):245-249.

7. Natale VM, Brenner IK, Moldoveanu Al, Vasiliou P, Shek P, Shephard Rf: Effects of three different types of exercise on blood leukocyte count during and following exercise. Sao Paulo Med J 2003, 121(1):9-14.

8. van Eeden SF, Granton J, Hards JM, Moore B, Hogg JC: Expression of the cell adhesion molecules on leukocytes that demarginate during acute maximal exercise. J Appl Physiol 1999, 86(3):970-976.

9. Simonson SR, Jackson CG: Leukocytosis occurs in response to resistance exercise in men. J Strength Cond Res 2004, 18(2):266-271.

10. Wilkinson DJ, Smeeton NJ, Watt PW: Ammonia metabolism, the brain and fatique; revisiting the link. Prog Neurobiol 2010, 91(3):200-219.

11. Muñoz MD, Monfort P, Gaztelu JM, Felipo V: Hyperammonemia impairs NMDA receptor-dependent long-term potentiation in the CA1 of rat hippocampus in vitro. Neurochem Res 2000, 25(4):437-441.

12. Felipo V, Butterworth RF: Neurobiology of ammonia. Prog Neurobiol 2002, 67(4):259-279

13. Bassini-Cameron A, Monteiro A, Gomes A, Werneck-de-Castro JP, Cameron L: Glutamine protects against increases in blood ammonia in football players in an exercise intensity-dependent way. $\mathrm{Br} J$ Sports Med 2008, 42(4):260-266.

14. Carvalho-Peixoto J, Alves RC, Cameron LC: Glutamine and carbohydrate supplements reduce ammonemia increase during endurance field exercise. Appl Physiol Nutr Metab 2007, 32(6):1186-1190.

15. de Almeida RD, Prado ES, Llosa CD, Magalhães-Neto A, Cameron LC: Acute supplementation with keto analogues and amino acids in rats during resistance exercise. Br J Nutr 2010, 104(10):1438-1442.

16. Prado ES, de Rezende Neto JM, de Almeida RD, Dória de Melo MG, Cameron LC: Keto analogue and amino acid supplementation affects the ammonaemia response during exercise under ketogenic conditions. $\mathrm{Br} J$ Nutr 2011 Feb, 16:1-5.

17. Morris SM Jr: Arginine: beyond protein. Am J Clin Nutr 2006, 83(Suppl 2):508-512.

18. Schaefer A, Piquard F, Geny B, Doutreleau S, Lampert E, Mettauer B, Lonsdorfer J: L-arginine reduces exercise-induced increase in plasma lactate and ammonia. Int J Sports Med 2002, 23(6):403-407.

19. Meneguello MO, Mendonça JR, Lancha AH Jr, Costa Rosa LF: Effect of arginine, ornithine and citrulline supplementation upon performance and metabolism of trained rats. Cell Biochem Funct 2003, 21(1):85-91.

20. Field CJ, Johnson I, Pratt VC: Glutamine and arginine: immunonutrients for improved health. Med Sci Sports Exerc 2000, 32(Suppl 7):377-388.

21. Tur-Marí J, Sureda A, Pons A: Blood cells as functional markers of antioxidant vitamin status. Br J Nutr 2006, 96(Suppl 1):38-41.

22. Resende NM, Magalhães-Neto AM, Bachini F, de Castro LEV, Bassini A, Cameron LC: Metabolic changes during a field experiment in a world-class windsurfing athlete: a trial with multivariate analyses. OMICS: A journal of integrative biology. 2011, 15(10):695-704.

23. Cameron LC: Mass spectrometry imaging: facts and perspectives from a non-mass spectrometrist point of view. Methods, 2012 in press. http://dx. doi.org/10.1016/j.ymeth.2012.06.007.

24. Ohtani $M$, Sugita $M$, Maruyama $K$ : Amino acid mixture improves training efficiency in athletes. J Nutr 2006, 136(Suppl 2):538-543.

25. Ravier G, Dugué B, Grappe F, Rouillon JD: Impressive anaerobic adaptations in elite karate athletes due to few intensive intermittent sessions added to regular karate training. Scand J Med Sci Sports 2009 19(5):687-94.

26. McConell GK, Canny BJ, Daddo MC, Nance MJ, Snow RJ: Effect of carbohydrate ingestion on glucose kinetics and muscle metabolism during intense endurance exercise. J Appl Physiol 2000, 89(5):1690-1698.

27. Nieman DC: Exercise, infection, and immunity. Int I Sports Med 1994, 15(Suppl 3):131-141

28. Kraemer WJ, Noble BJ, Clark MJ, Culver BW: Physiologic responses to heavy-resistance exercise with very short rest periods. Int I Sports Med 1987, 8(4):247-252

29. Kraemer WJ, Clemson A, Triplett NT, Bush JA, Newton RU, Lynch JM: The effects of plasma cortisol elevation on total and differential leukocyte counts in response to heavy-resistance exercise. Eur J Appl Physiol Occup Physiol 1996, 73(1-2):93-97.

30. Boyum A, Ronsen O, Tennfjord VA, Tollefsen S, Haugen AH, Opstad PK Bahr R: Chemiluminescence response of granulocytes from elite athletes during recovery from one or two intense bouts of exercise. Eur J Appl Physiol 2002, 88(1-2):20-28.

31. Northoff $H$, Berg A, Weinstock C: Similarities and differences of the immune response to exercise and trauma: the IFN-gamma concept Can J Physiol Pharmacol 1998, 76(5):497-504.

32. Cuzzolin L, Lussignoli S, Crivellente F, Adami A, Schena F, Bellavite P, Brocco G, Benoni G: Influence of an acute exercise on neutrophil and platelet adhesion, nitric oxide plasma metabolites in inactive and active subjects. Int J Sports Med 2000, 21(4):289-293.

33. Carlson LA, Headley S, DeBruin J, Tuckow AT, Koch AJ, Kenefick RW: Carbohydrate supplementation and immune responses after acute exhaustive resistance exercise. Int I Sport Nutr Exerc Metab 2008, 18(3):247-259.

34. Garg SK, Baneriee R, Kipnis J: Neuroprotective immunity: T cell-derived glutamate endows astrocytes with a neuroprotective phenotype. $J$ Immunol 2008, 180(6):3866-3873.

35. Moalem G, Leibowitz-Amit R, Yoles E, Mor F, Cohen IR, Schwartz M: Autoimmune $T$ cells protect neurons from secondary degeneration after central nervous system axotomy. Nat Med 1999, 5(1):49-55. 
36. Moalem G, Yoles E, Leibowitz-Amit R, Muller-Gilor S, Mor F, Cohen IR,

Schwartz M: Autoimmune T cells retard the loss of function in injured rat optic nerves. J Neuroimmunol 2000, 106(1-2):189-197.

37. Kipnis J, Cohen H, Cardon M, Ziv Y, Schwartz M: T cell deficiency leads to cognitive dysfunction: implications for therapeutic vaccination for schizophrenia and other psychiatric conditions. Proc Natl Acad Sci U S A 2004, 101(21):8180-8185.

doi:10.1186/1550-2783-9-30

Cite this article as: Gonçalves et al:: A sportomics strategy to analyze the ability of arginine to modulate both ammonia and lymphocyte levels in blood after high-intensity exercise. Journal of the International Society of

Sports Nutrition 2012 9:30.

\section{Submit your next manuscript to BioMed Central and take full advantage of:}

- Convenient online submission

- Thorough peer review

- No space constraints or color figure charges

- Immediate publication on acceptance

- Inclusion in PubMed, CAS, Scopus and Google Scholar

- Research which is freely available for redistribution 